\title{
BMJ Open Occurrence and mortality of vasospastic angina pectoris hospitalised patients in Finland: a population-based registry cohort study
}

Essi Pikkarainen, ${ }^{1}$ Juuso Blomster, ${ }^{2}$ Jussi Sipilä, ${ }^{3,4,5}$ Päivi Rautava, ${ }^{6}$ Ville Kytö ${ }^{2}$

To cite: Pikkarainen E, Blomster J, Sipilä J, et al. Occurrence and mortality of vasospastic angina pectoris hospitalised patients in Finland: a population-based registry cohort study. BMJ Open 2019;9:e030768. doi:10.1136/ bmjopen-2019-030768

- Prepublication history for this paper is available online. To view these files, please visit the journal online (http://dx.doi org/10.1136/bmjopen-2019030768).

Received 16 April 2019

Revised 18 September 2019

Accepted 19 September 2019

\section{Check for updates}

(C) Author(s) (or their employer(s)) 2019. Re-use permitted under CC BY-NC. No commercial re-use. See rights and permissions. Published by BMJ.

${ }^{1}$ Heart Centre, Päijät-Häme Central Hospital, Lahti, Finland ${ }^{2}$ Heart Centre, Turku University Hospital, Turku, Finland

${ }^{3}$ Division of Clinical

Neurosciences, Turku University Hospital, Turku, Finland

${ }^{4}$ Department of Neurology,

Turku University Hospital, Turku,

Finland

${ }^{5}$ Department of Neurology, Siun Sote, North Carelia Central Hospital, Joensuu, Finland

${ }^{6}$ Clinical Research Centre Turku, Turku University Hospital, Turku, Finland

Correspondence to

Dr Essi Pikkarainen;

essi.pikkarainen@fimnet.fi

\section{ABSTRACT}

Objectives The occurrence and mortality of vasospastic angina pectoris (VAP) is largely unknown in western countries. Our objective was to clarify the occurrence, gender-distribution and mortality of VAP in Finland using a population-based hospital registry.

Methods We studied consecutive patients aged $\geq 18$ years hospitalized with VAP as the primary cause of admission in Finland during 2004-2014. The data were collected from obligatory nationwide registries. During the study period 1762 admissions were recorded.

Results Majority of all VAP patients were male (59.7\%) and mean age was $65.7 \pm 12.0$ years. Annual admission rate for VAP was 2.29/100000 person-years. Men were in higher risk for VAP than women (admission rate $3.00 / 100000$ vs $1.68 / 100000$; RR 1.70; $p<0.0001$ ). Gender difference was not modified by age. Likelihood of VAP was highest in population aged 70-84 years. Admission rate for VAP decreased notably during the study period. One-year all-cause mortality was $8.0 \%$ and 3-year mortality was $15.5 \%$ (cardiac mortality $11.1 \%$ ). Mortality was associated with increasing age, comorbidity burden and lack of detected coronary artery obstruction, but was similar between genders and during the study period. Conclusions Men have higher risk for vasospastic angina caused admissions. Likelihood of vasospastic angina admission was highest in aged population. The 3-year allcause mortality was $15.5 \%$. Mortality was associated with increasing age, comorbidities and non-obstructive VAP diagnosis but was similar between genders.

\section{INTRODUCTION}

Vasospastic angina pectoris (VAP), or Prinzmetal's angina, originally described by Myron Prinzmetal et $a l,{ }^{1}$ is defined as a sudden coronary vasoconstriction leading to excessively reduced coronary blood flow causing myocardial ischaemia. ${ }^{2}$ The definite VAP diagnosis involves three considerations: (1) classical clinical manifestations of VAP (spontaneous nitrate responsive angina episodes), (2) documentation of myocardial ischaemia during spontaneous episodes, (3) demonstration of coronary artery spasm. ${ }^{3}{ }^{4}$ Coronary spasms occur mainly in large epicardial
Strengths and limitations of this study

New information about the vasospastic angina pectoris patients in a western country.

- Unique registry data including all medical hospitals admissions with the diagnoses of vasospastic angina from all hospitals treating acute cardiac patients in mainland Finland.

Follow-up period of 11 years.

- Retrospective registry data and the diagnoses were made by different physicians.

- Coronary angiography was performed for $56 \%$ of the hospitalised patients limiting the accuracy of diagnoses.

arteries but are known to occur also in coronary microvasculature of the myocardium. Coronary spasms may be associated with sclerotic lesions in the arterial walls. ${ }^{35}$

The prevalence of VAP seems to vary in different patient populations, but it has been reported that about $40 \%$ of the angina patients have vasospastic angina ${ }^{3}$ and vasospasm have been detected in a third of non-ST-elevation myocardial infarction (MI) patients. ${ }^{6}$ In more detail, VAP is well studied in Japanese population and appears more common in oriental countries in comparison to western countries. Also, there seem to be substantial differences between Caucasian and Japanese VAP patients ${ }^{37}$ with Japanese patients having more diffusely hypersensitive coronary arteries. ${ }^{8}$

The 3-year MI mortality of VAP patients has been reported to be $3 \%$ in Japanese populations and $2 \%$ in Korean population. ${ }^{3910}$ Threeyear MI mortality in western VAP population has been $11 \% .^{3}$ In Caucasian VAP patients with non-significant coronary obstructions, the all-cause mortality was $24 \%$ in a 140 months follow-up and the deaths were mostly age-related. $^{11}$ 


\begin{tabular}{|c|c|c|c|c|}
\hline Variable & Total $(n=1762)$ & Male $(n=1052)$ & Female $(n=710)$ & $P$ value* \\
\hline Age (y, mean) & $65.7 \pm 12.0$ & $64.9 \pm 11.3$ & $66.8 \pm 13.0$ & 0.002 \\
\hline $\mathrm{CCl}$ score & & & & 0.178 \\
\hline 0 & $975(55.3 \%)$ & $576(54.8 \%)$ & $399(56.2 \%)$ & \\
\hline 1 & 415 (23.6\%) & $246(23.4 \%)$ & $169(23.8 \%)$ & \\
\hline 2 & $224(12.7 \%)$ & $131(12.5 \%)$ & $93(13.1 \%)$ & \\
\hline$\geq 3$ & 148 (8.4\%) & $99(9.4 \%)$ & $49(6.9 \%)$ & \\
\hline Coronary angiography performed† & $992(56.3 \%)$ & $614(58.4 \%)$ & $378(53.2 \%)$ & 0.033 \\
\hline Angiographical finding & & & & $<0.0001$ \\
\hline No obstruction & $793(45.0 \%)$ & $440(41.8 \%)$ & $353(49.7 \%)$ & \\
\hline Obstruction & $498(28.3 \%)$ & $346(32.9 \%)$ & $152(21.4 \%)$ & \\
\hline NAS & $471(26.7 \%)$ & $266(25.3 \%)$ & $205(28.9 \%)$ & \\
\hline
\end{tabular}

${ }^{*}$ Between genders.

†During vasospastic angina pectoris admission.

$\mathrm{CCl}$, Charlson comorbidity index; NAS, Not otherwise specified.

Several VAP patient series and registries originating mainly from oriental populations have been reported whereas to our knowledge the occurrence of VAP at population level in western countries is less well studied. We set out to clarify the occurrence, gender-distribution and mortality of VAP in Finland using a population-based hospital registry.

\section{METHODS}

\section{Study population}

We studied patients aged $\geq 18$ years hospitalised with VAP (ICD-10 code I20.1X) as the primary cause of admission. Data of all medical hospitals admissions from all hospitals treating acute cardiac patients in mainland Finland between 1 January 2004 and 31 December 2014 were retrospectively collected from the Care Register for Health Care, a nationwide database containing all hospital discharge data from all admissions in Finland and maintained by the Finnish National Institute for Health and Welfare. VAP types were classified based on ICD-10 coding and the performed operations were identified based on operational codes (Nordic Classification of Surgical Procedures).

Finnish hospital system consists of three main levels: university hospitals $(n=5)$ representing the highest level of hierarchy, followed by central hospitals $(n=16)$ with coronary catherisation laboratories and intensive care units, and then several smaller regional hospitals. Admissions due to VAP occurred in 38 hospitals during the study period (33\% in university hospitals, $54 \%$ in central hospitals and $13 \%$ in regional hospitals). Mortality and cause of death data (follow-up ended in 31.12.2014) for the identified patients were obtained from nationwide and obligatory cause of death registry held by Statistics Finland. The comorbidities of the patients were described by Charlson comorbidity index (CCI). Annual admissions rates (one admission per year) were estimated by using age-matched and gender-matched population data of mainland Finland from the study period (46642940 person-years) obtained from Statistics Finland.

\section{Statistical analysis}

Scale variables are presented as mean \pm SD and categorical variables are presented as counts or percentages with 95\% CIs when applicable. Gender differences in baseline features were analysed using t-test or $\chi^{2}$ test. Count data were analysed by using negative binomial regression models. In the regression models of annual admission rate, the logarithm of population was used as an offset parameter.

All-cause mortality from first VAP admission was studied using Kaplan-Maier method and Cox regression. Duration of hospital admission was calculated as beginning days.

Results of regression analyses are given as rate ratios (RR) or HRs as appropriate. CCI was calculated according to previously used algorithm. ${ }^{12}$ Admission rates of admissions (one admission per year) were standardised to WHO 2010 standard population with the use of a direct method as appropriate. $\mathrm{P}$ values $<0.05$ were considered statistically significant. Analyses were performed with the SAS system V.9.4.

\section{Patient and public involvement}

This study is based on a retrospective registry data and does not have direct involvement of patients or the public.

\section{RESULTS}

\section{Patient features}

VAP was the primary cause for 1762 hospital admissions (1570 individual patients, 59.7\% male) during the study period. Demographic baseline characteristics of the hospitalised patients are shown in table 1. Mean age of all VAP patients was $65.7 \pm 12.0$ years (range 18-98 

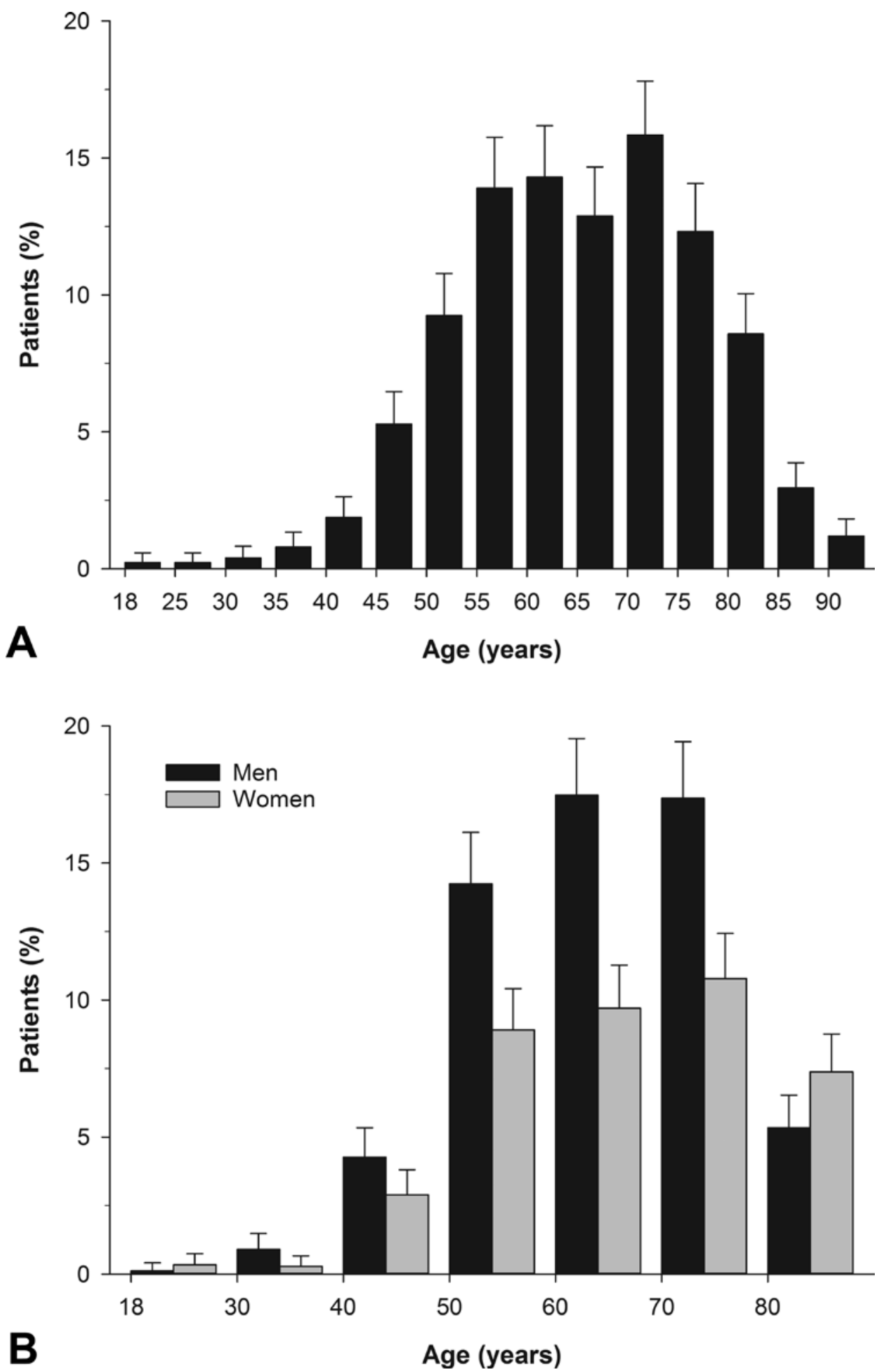

Figure 1 Frequency of vasospastic angina pectoris admissions. Age-distribution of all patients (A) and by gender (from total number of patients) (B). Error bars represent upper limits of $95 \%$ Cls.

years) (figure 1A). Age distribution of VAP patients had similar patterns in both genders, although age-pattern was shifted towards older age in women (figure 1B) with female patients being marginally older compared with men (table 1). Comorbidity burden of patients was similar between genders (table 1). Coronary angiography was performed in 56\% admissions and was more common for men than for women, who were hospitalised for VAP (table 1). Majority of VAP patients had no detected coronary obstruction, but obstructive disease was more common in men than in women (table 1). Admission for vasospastic angina lasted on average for 4.3 \pm 3.7 (range 1-44 days) with no difference in duration of admission between genders. MI (I21.X) 


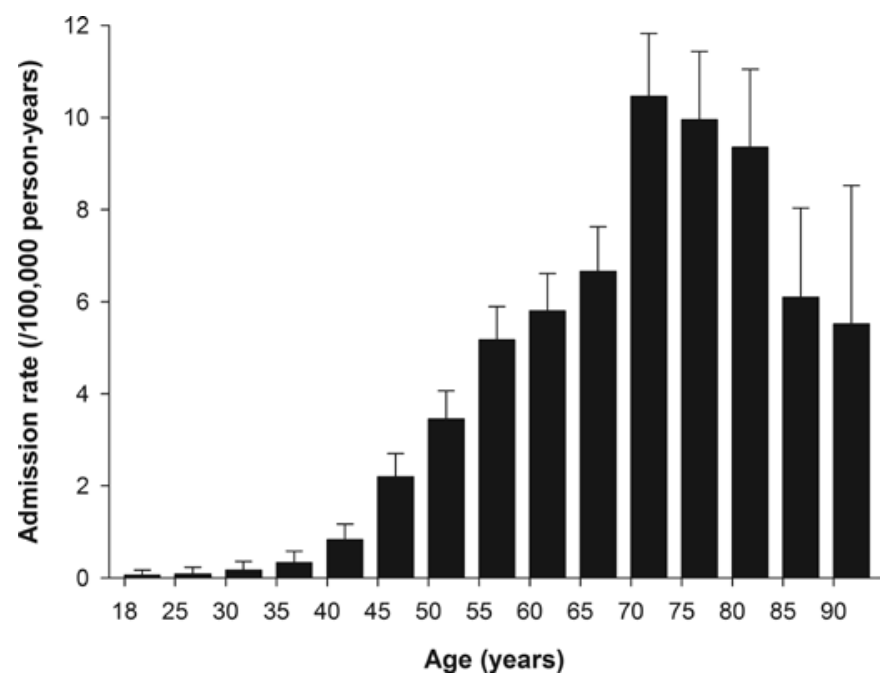

Figure 2 Annual rate of vasospastic angina pectoris admission in general adult population. Admission rates (per 100000 person-years) by age. Error bars represent upper limits of $95 \%$ Cls.

was secondary or a tertiary diagnosis for $1.8 \%$ of VAP patients.

\section{Annual admission rate}

During the whole study period, the total standardised annual admission rate for VAP was 2.29 (95\% CI 2.15 to 2.43 ) /100 000 person-years (crude rate 3.45 (95\% CI

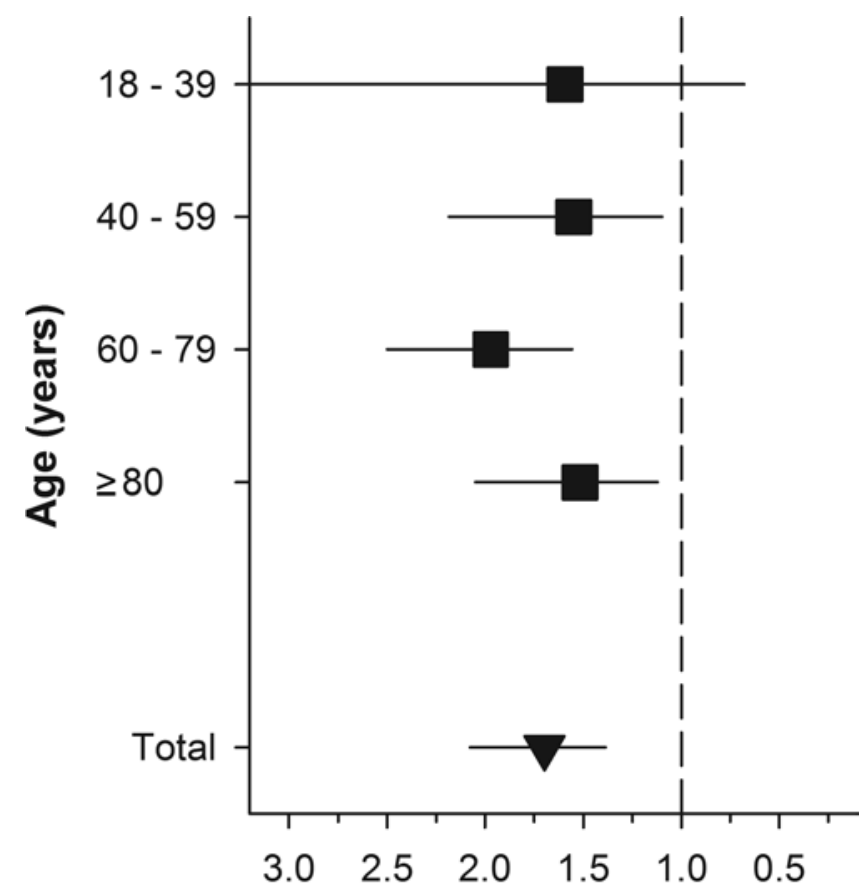

Rate Ratio (men : women)

Figure 3 Gender-associated admission rate ratio of vasospastic angina pectoris by age in general population. Ratio is calculated as men versus women and adjusted for background population and study year. Error bars represent 95\% Cls.

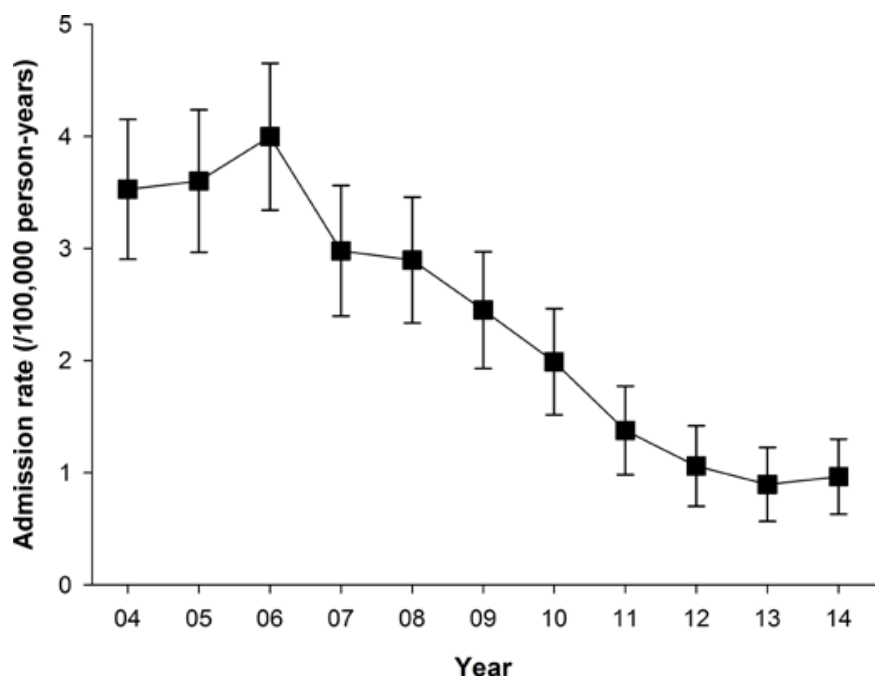

Figure 4 Trend for annual rate of vasospastic angina pectoris admissions in general adult population. Standardised to who standard population. Error bars represent 95\% Cls.

3.29 to 3.63$) / 100$ 000). Likelihood of VAP admission increased progressively from 40 to 70 years of age with highest rate $(10.5 / 100000)$ in patients aged $70-75$ years (figure 2). Among women, the standardised overall rate for VAP hospital admission was 1.68 (95\% CI 1.52 to 1.86)/100 000 person-years (crude rate 2.71 (95\% CI 1.52 to 1.86$) / 100000$ ), whereas for men the standardised rate was 3.00 (95\% CI 2.77 to 3.22 ) $/ 100000$ (crude rate 4.25 (95\% CI 3.98 to 4.53$) / 100000)$. In total Finnish adult population, men were $70 \%$ more likely to be admitted to hospital due to VAP (RR for admission rate 1.70; 95\% CI 1.39 to $2.08 ; \mathrm{p}<0.0001)$ than women. Gender difference was similar between age groups (interaction $\mathrm{p}=0.201$ ) (figure 3). Admission rate for VAP decreased notably during the study period (figure 4).

\section{Mortality}

Thirty-day all-cause mortality was 3.2\%, 1-year mortality was $8.0 \%$ and 3-year mortality was $15.5 \%$ after admission for VAP (figure 5). One-year mortality was associated with increasing age, comorbidity burden and coronary artery status, but was similar between genders and study periods (table 2). Comparably, 3-year mortality was associated with increasing age, CCI-score and lack of detected coronary artery obstruction but was similar between genders during study (table 3). Majority (71.2\%) of all the deaths were due to cardiac causes with cardiac mortality of $5.8 \%$ at 1-year and $11.1 \%$ at 3-year follow-up. MI and ischaemic heart disease were most common underlying causes of death.

\section{DISCUSSION}

This nationwide study describes the occurrence of VAP admissions in Finnish general population. Men were $70 \%$ more likely to be admitted for VAP compared with woman. All-cause mortality was $8.0 \%$ at 1 year and $15.5 \%$ at 3 years. Mortality was associated with older age, 


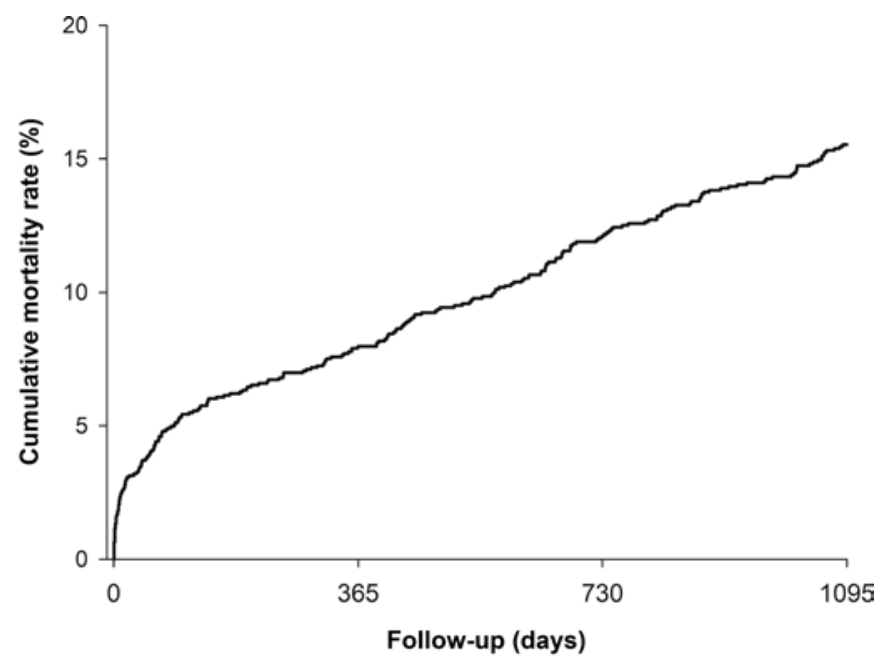

Pt. at risk.

$1570 \quad 1390 \quad 1280 \quad 1180$

Figure 5 Cumulative all-cause mortality after vasospastic angina pectoris admission.

comorbidities and non-obstructive or non-specific coronary findings but it was similar between genders.

The diagnosis of vasospastic angina is characterised by spontaneous chest pains and drug or non-drug (ie, hyperventilation) induced spasm. The gold standard of coronary artery spasm testing involves the administration of a provocative stimulus during coronary angiography. ${ }^{4}$ In our study population, coronary angiography was undertaken in $58 \%$ of men and in $53 \%$ of women hospitalised for VAP.

It is known from previous studies that coronary spasm may develop in sclerotic lesions of varying severity. ${ }^{35}$ Even if no stenotic lesions are visible on coronary angiography, intravascular ultrasound (IVUS) commonly reveals arteriosclerotic lesions in locations consistent with regions of coronary spasm. ${ }^{3}$ It has been shown that with optical coherence tomography (OCT), thrombus was seen in one-fourth of patients with vasospastic angina and luminal irregularity was observed in nearly two-thirds of the study patients. ${ }^{5}$ In the present study, atherosclerotic changes in coronary arteries were diagnosed in $33 \%$ of men and $21 \%$ of women.

We found the overall annual admission rate for VAP to be $2.3 / 100000$. This compares to previously detected admission rates of $93 / 100000$ for unstable angina pectoris, ${ }^{13} 105 / 100000$ for ST-elevation MI $^{14}$ and 206/100000 for non-ST-elevation $\mathrm{MI}^{15}$ in Finnish adult population. Volume of VAP admissions can thus be

Table 2 Factors associated with 1-year all-cause mortality. Univariate and multivariate analysis

\begin{tabular}{|c|c|c|c|c|c|c|c|}
\hline \multirow[b]{2}{*}{ Variable } & \multirow{2}{*}{$\begin{array}{l}\text { Mortality } \\
(\%)\end{array}$} & \multicolumn{3}{|c|}{ Univariate } & \multicolumn{3}{|c|}{ Multivariate } \\
\hline & & HR & $95 \% \mathrm{Cl}$ & P value & HR & $95 \% \mathrm{Cl}$ & $P$ value \\
\hline Gender & & & & 0.795 & & & 0.311 \\
\hline Male & 7.82 & Ref. & & & & & \\
\hline Female & 8.19 & 1.05 & 0.73 to 1.50 & 0.795 & 0.83 & 0.57 to 1.19 & 0.311 \\
\hline Age (years) & & & & $<0.0001$ & & & $<0.0001$ \\
\hline$<50$ & 2.16 & Ref. & & & Ref. & & \\
\hline $50-59$ & 0.85 & 0.4 & 0.08 to 2.00 & 0.267 & 0.4 & 0.08 to 1.97 & 0.259 \\
\hline $60-69$ & 5.46 & 2.62 & 0.79 to 8.71 & 0.117 & 2.25 & 0.67 to 7.53 & 0.189 \\
\hline $70-79$ & 10.26 & 5.03 & 1.56 to 16.19 & 0.007 & 4.15 & 1.28 to 13.45 & 0.018 \\
\hline $80-$ & 24.26 & 13.12 & 4.09 to 42.06 & $<0.0001$ & 9.95 & 3.06 to 32.33 & 0.0001 \\
\hline $\mathrm{CCl}$ & & & & $<0.0001$ & & & $<0.0001$ \\
\hline 0 & 4.18 & Ref. & & & Ref. & & \\
\hline 1 & 7.82 & 1.88 & 1.15 to 3.07 & 0.011 & 1.47 & 0.90 to 2.42 & 0.127 \\
\hline 2 & 17.39 & 4.39 & 2.75 to 7.02 & $<0.0001$ & 2.68 & 1.65 to 4.36 & $<0.0001$ \\
\hline$\geq 3$ & 19.23 & 4.82 & 2.89 to 8.03 & $<0.0001$ & 3.33 & 1.97 to 5.64 & $<0.0001$ \\
\hline Coronary status & & & & 0.006 & & & 0.149 \\
\hline Obstruction & 4.55 & Ref. & & & Ref. & & \\
\hline No obstruction & 8.36 & 1.87 & 1.12 to 3.14 & 0.017 & 1.69 & 0.99 to 2.87 & 0.05 \\
\hline NAS & 10.67 & 2.41 & 1.41 to 4.12 & 0.001 & 1.51 & 0.87 to 2.65 & 0.155 \\
\hline Study year & & & & 0.198 & & & 0.564 \\
\hline 2004-2006 & 7.26 & Ref. & & & Ref. & & \\
\hline 2007-2010 & 7.62 & 1.05 & 0.70 to 1.56 & 0.821 & 0.99 & 0.66 to 1.49 & 0.97 \\
\hline 2010-2014 & 10.79 & 1.44 & 0.90 to 2.31 & 0.086 & 1.26 & 0.78 to 2.07 & 0.338 \\
\hline
\end{tabular}

$\mathrm{CCl}$, Charlson comorbidity index; NAS, Not otherwise specified. 
Table 3 Factors associated with 3-year all-cause mortality. Univariate and multivariate analysis

\begin{tabular}{|c|c|c|c|c|c|c|c|}
\hline \multirow[b]{2}{*}{ Variable } & \multirow{2}{*}{$\begin{array}{l}\text { Mortality } \\
(\%)\end{array}$} & \multicolumn{3}{|c|}{ Univariate } & \multicolumn{3}{|c|}{ Multivariate } \\
\hline & & HR & $95 \% \mathrm{Cl}$ & $P$ value & HR & $95 \% \mathrm{Cl}$ & $P$ value \\
\hline Gender & & & & 0.788 & & & 0.065 \\
\hline Male & 15.78 & Ref. & & & & & \\
\hline Female & 15.15 & 0.97 & 0.74 to 1.26 & 0.788 & 0.78 & 0.59 to 1.02 & 0.065 \\
\hline Age (years) & & & & $<0.0001$ & & & $<0.0001$ \\
\hline$<50$ & 4.6 & Ref. & & & Ref. & & \\
\hline $50-59$ & 5.09 & 1.1 & 0.44 to 2.80 & 0.835 & 1.08 & 0.42 to 2.74 & 0.876 \\
\hline $60-69$ & 10.27 & 2.35 & 1.00 to 5.53 & 0.05 & 2.05 & 0.87 to 4.84 & 0.102 \\
\hline $70-79$ & 20.22 & 4.84 & 2.12 to 11.07 & 0.0002 & 4.13 & 1.80 to 9.48 & 0.0008 \\
\hline $80-$ & 41.33 & 11.78 & 5.14 to 26.98 & $<0.0001$ & 9 & 4.02 to 21.52 & $<0.0001$ \\
\hline $\mathrm{CCl}$ & & & & $<0.0001$ & & & $<0.0001$ \\
\hline 0 & 9.65 & Ref. & & & Ref. & & \\
\hline 1 & 14.57 & 1.57 & 1.11 to 2.23 & 0.01 & 1.25 & 0.88 to 1.78 & 0.208 \\
\hline 2 & 28.87 & 3.42 & 2.43 to 4.82 & $<0.0001$ & 2.29 & 1.61 to 3.27 & $<0.0001$ \\
\hline$\geq 3$ & 36.65 & 4.36 & 3.03 to 6.27 & $<0.0001$ & 3.26 & 2.17 to 4.59 & $<0.0001$ \\
\hline Coronary status & & & & $<0.0001$ & & & 0.045 \\
\hline Obstruction & 10.08 & Ref. & & & Ref. & & \\
\hline No obstruction & 15.15 & 1.56 & 1.09 to 2.24 & 0.016 & 1.51 & 1.05 to 2.19 & 0.028 \\
\hline NAS & 21.67 & 2.3 & 1.59 to 3.34 & $<0.0001$ & 1.61 & 1.09 to 2.37 & 0.017 \\
\hline Study year & & & & 0.311 & & & 0.609 \\
\hline 2004-2006 & 15.26 & Ref. & & & Ref. & & \\
\hline 2007-2010 & 14.76 & 0.96 & 0.73 to 1.28 & 0.796 & 0.8 & 0.68 to 1.21 & 0.511 \\
\hline 2010-2014 & 17.81 & 1.29 & 0.89 to 1.87 & 0.188 & 1.1 & 0.75 to 1.6 & 0.64 \\
\hline
\end{tabular}

$\mathrm{CCl}$, Charlson comorbidity index; NAS, Not otherwise specified.

estimated to be approximately $1 \%$ of the amount of acute coronary syndrome (ACS) admissions. Decreasing VAP admissions are however, likely to affect this ratio.

In Japan as well as in western countries vasospastic angina is more prevalent in males. The gender-difference diminishes after menopause and disappears at the age of 80 in Japanese population. ${ }^{3}$ We found VAP to be $70 \%$ more common among men while gender-difference was not modified by age. VAP is known to cause significant morbidity to individuals affected. ${ }^{16}$ In Korean population mortality was $2 \%$ at 2 years ${ }^{5}$ with similar prognosis in both genders. ${ }^{17}$ In a Japanese study population, the MI was $3 \%$ at 3 years. ${ }^{3}$ In western population the 3 -year MI mortality has been reported to be $11 \%^{3}$ comparably to our results.

In Caucasian study population of VAP without significant atherosclerotic stenosis, the mortality was $24 \%$ at 12-year follow-up with mostly non-cardiac deaths. ${ }^{11}$

We found 3-year mortality to be $15.5 \%$ and to be mostly cardiogenic. In an earlier study, the risk of death and MI was similar in male ST-segment elevation MI patients and VAP patients while VAP patients with non-significant coronary stenosis seemed to have less complications and lower mortality. ${ }^{18}$
Our results suggest that the VAP might not be as benign disease as often thought. We can assume, that most the of patients with a diagnostic code of narrowing or occlusive coronary artery findings, had a visible narrowing or occlusion in the coronary arteries and had been taken care of by intervention or medication for coronary artery decease in the well-functioning Finnish healthcare system. For rest of the study population, coronary angiography did not reveal atherosclerotic changes, or the angiography was not performed during index admission. For comparison, in a Swedish register study, the 1-year mortality after admission for unstable angina pectoris was $10 \%$ in age group $65-105 .{ }^{19}$ Interestingly, a Korean study found VAP patients presenting with ACS to have worse prognosis compared with VAP patients without presentation of ACS. ${ }^{9}$ One potential mechanism for VAP related mortality are vasospasm triggered arrythmias. In agreement, previous studies have shown VAP patients with aborted sudden cardiac death to have worse prognosis than those without. ${ }^{1620}$

In North America, vasospastic angina has become less frequent for unknown reasons, possibly relating to more widespread use of calcium antagonists. ${ }^{21} \mathrm{Up}$ to $70 \%$ of patients with ACS presenting with typical ECG changes 
and/or elevation of cardiac markers had culprit lesions, whereas the remaining $30 \%$ of ACS patients had no obstructive coronary artery lesions. Cardiologists in the USA do not perform spasm provocation tests routinely in patients with non-obstructive coronary artery disease with chest pain/discomfort in the cardiac catheterisation laboratory. ${ }^{21}$ Similarly, in our study, the occurrence of VAP admissions decreased notably during the study period. Underling reason for this change is unknown. In addition to true decrease in VAP, this finding may relate to increase in rates of Takotsubo cardiomyopathy diagnoses $^{22}$ and high-sensitive troponin assay usage increasing alternative diagnoses for VAP during the study period.

The present study has some limitation. A major limitation is the retrospective nature of observational registry data without access to more detailed clinical or therapeutic data. Diagnoses were based on the treating physician's clinical impression and this may not have fulfilled published diagnostic criteria. This may have affected the selected study population and the accuracy of the comorbidity data. In addition, because our data included only hospitalised patients, the results under-represents patients with low-risk features who may have been treated without being admitted to the hospital or who have not sought for help. Coronary angiography was performed only for $56 \%$ of VAP patients. Some of the coronary artery disease diagnoses might thus have been missed. Furthermore, the spasm provocation tests are seldomly used in Finland limiting the accuracy of VAP diagnoses.

In conclusion, our results suggest that men have higher risk for vasospastic angina causing admissions compared with women. Likelihood of vasospastic angina admission was highest in population aged 70-84 years. The 3-year mortality was $15.5 \%$ and was predicted by patients age and comorbidities, but also by non-obstructive vasospastic angina diagnosis. The cause of death was mostly cardiac at 1-year and 3-year follow-ups. These results may help characterise the inadequately known epidemiology of VAP in western countries.

Correction notice This article has been corrected since it was published. Affiliation for Jussi Slpilä is updated. Figure 4 and 5 have been interchanged.

Contributors EP data interpretation, manuscript writing and editing; JB manuscript writing and editing; JS and PR proofreading and manuscript editing; VK study design, data collection/analysis/interpretation, manuscript writing and editing, study supervision.

Funding This work was supported by the Clinical Research Foundation of Turku University Hospital, the Finnish Cardiac Society and the Finnish Cultural Foundation.

Competing interests None declared.

Patient consent for publication Not required.

Ethics approval The National Institute for Health and Welfare of Finland (permissions no: THL/143/5.05.00/2015 and THL/1569/5.05.00/2016) and Statistics Finland (TK53-1410-15) approved the study.

Provenance and peer review Not commissioned; externally peer reviewed.

Data availability statement All data relevant to the study are included in the article or uploaded as supplementary information.
Open access This is an open access article distributed in accordance with the Creative Commons Attribution Non Commercial (CC BY-NC 4.0) license, which permits others to distribute, remix, adapt, build upon this work non-commercially, and license their derivative works on different terms, provided the original work is properly cited, appropriate credit is given, any changes made indicated, and the use is non-commercial. See: http://creativecommons.org/licenses/by-nc/4.0/.

\section{REFERENCES}

1 Prinzmetal M, Kennamer R, Merliss R, et al. Angina pectoris. I. A variant form of angina pectoris; preliminary report. Am J Med 1959;27:375-88.

2 Shimokawa H. 2014 Williams Harvey Lecture: importance of coronary vasomotion abnormalities-from bench to bedside. Eur Heart J 2014;35:3180-93.

3 JCS Joint Working Group. Guidelines for diagnosis and treatment of patients with vasospastic angina (coronary spastic angina) (JCS 2013). Circ J 2014;78:2779-801.

4 Beltrame JF, Crea F, Kaski JC, et al. International standardization of diagnostic criteria for vasospastic angina. Eur Heart $J$ 2017;38:2565-8.

5 Shin E-S, Ann SH, Singh GB, et al. OCT-defined morphological characteristics of coronary artery spasm sites in vasospastic angina. JACC Cardiovasc Imaging 2015;8:1059-67.

6 Nakayama N, Kaikita K, Fukunaga T, et al. Clinical features and prognosis of patients with coronary spasm-induced non-STsegment elevation acute coronary syndrome. J Am Heart Assoc 2014;3:e000795.

7 Beltrame JF, Crea F, Kaski JC, et al. The who, what, why, when, how and where of vasospastic angina. Circ J 2016;80:289-98.

8 Beltrame JF, Sasayama S, Maseri A. Racial heterogeneity in coronary artery vasomotor reactivity: differences between Japanese and Caucasian patients. J Am Coll Cardiol 1999;33:1442-52.

9 Cho SW, Park TK, Gwag HB, et al. Clinical outcomes of vasospastic angina patients presenting with acute coronary syndrome. J Am Heart Assoc 2016;5:e004336.

10 Shin DIL, Seung K-B, Seo SM, et al. The long-term cardiac mortality and the rate of percutaneous coronary intervention in Korean patients with vasospastic angina. J Am Coll Cardiol 2012;59:E1490.

11 Figueras J, Domingo E, Ferreira I, et al. Persistent angina pectoris, cardiac mortality and myocardial infarction during a 12 year followup in 273 variant angina patients without significant fixed coronary stenosis. Am J Cardiol 2012;110:1249-55.

12 Quan H, Sundararajan V, Halfon P, et al. Coding algorithms for defining comorbidities in ICD-9-CM and ICD-10 administrative data. Med Care 2005;43:1130-9.

13 Kytö V, Sipilä J, Rautava P. Gender-specific and age-specific differences in unstable angina pectoris admissions: a populationbased registry study in Finland. BMJ Open 2015;5:e009025.

14 Kytö V, Sipilä J, Rautava P. Gender, age and risk of ST segment elevation myocardial infarction. Eur J Clin Invest 2014;44:902-9.

15 Kytö V, Sipilä J, Rautava P. Association of age and gender with risk for non-ST-elevation myocardial infarction. Eur J Prev Cardiol 2015;22:1003-8.

16 Ahn J-M, Lee KH, Yoo S-Y, et al. Prognosis of Variant Angina Manifesting as Aborted Sudden Cardiac Death. J Am Coll Cardiol 2016;68:137-45.

17 Lee DH, Park TK, Seong CS, et al. Gender differences in long-term clinical outcomes and prognostic factors in patients with vasospastic angina. Int J Cardiol 2017;249:6-11.

18 Figueras J, Cortadellas J, Gil CP, et al. Comparison of clinical and angiographic features and longterm follow-up events between patients with variant angina and patients with ST elevation myocardial infarction. Int J Cardiol 2006;111:256-62.

19 Dudas K, Björck L, Jernberg T, et al. Differences between acute myocardial infarction and unstable angina: a longitudinal cohort study reporting findings from the register of information and knowledge about Swedish heart intensive care admissions (RIKSHIA). BMJ Open 2013;3:e002155.

20 Kundu A, Vaze A, Sardar P, et al. Variant angina and aborted sudden cardiac death. Curr Cardiol Rep 2018;20:26.

21 Sueda S, Sasaki Y, Sakaue T. Recommendation for establishment of guidelines for Prinzmetal's variant angina and vasospastic angina in the USA and Europe. J Cardiol Cases 2012;6:e161-2.

22 Templin C, Ghadri JR, Diekmann J, et al. Clinical features and outcomes of takotsubo (stress) cardiomyopathy. N Engl J Med Overseas Ed 2015;373:929-38. 